\title{
NUMERICAL SIMULATION OF GAS TURBINE BLADE COOLING FOR ENHANCEMENT OF HEAT TRANSFER OF THE BLADE TIP
}

\author{
Sushil Sunil Gaikwad ${ }^{1}$, C. R. Sonawane ${ }^{2}$ \\ ${ }^{I}$ PG Student, Mechanical Engg Dept, Pimpri Chinchwad College of Engg, Pune, Maharashtra, India \\ ${ }^{2}$ Asso. Prof, Mechanical Engg Dept, Pimpri Chinchwad College of Engg, Pune, Maharashtra, India
}

\begin{abstract}
In today's industrial scenario, Gas Turbine is one of the most important components of auxiliary power plant system. In order maximize the overall performance and efficiency of all modern turbines, which theoretically operate according to Brayton cycle, they are operated at a very high temperature. These temperatures are so high that, which may fall in the region of turbine blade material melting point temperatures. Due to such high temperatures there is a possibility that the turbine blades may get damaged due to produced thermal stresses and presents a possible threat to the turbine system as well as the operators. Hence to ensure safe and reliable working of the turbines an effective and reliable cooling system is necessary. Currently available methods for cooling of the turbine blades include film cooling with impingement cooling for the leading edge, rib turbulated cooling using serpentine passages for the middle portion of the blade and pin fin cooling for the trailing edge of the turbine blades. The cooling mechanism for turbine blades must include cooling for all possible regions which are exposed to hot gas flow. The turbine blade tip is one of the critical regions which are severely exposed to hot gas flow occurring due to the leakage of gases from the clearance gap between the turbine tip and the shroud. Hence the tip of the turbine blade must be cooled effectively to prevent thermal expansion of the turbine blade tip due to heating. This cooling will eventually help to avoid rubbing of blades to the shroud which may cause their wear. In this paper the effect of provision of pins of two different diameters and heights over the turbine blade tip at the corners, on the heat transfer has been investigated. The results obtained were compared with the heat transfer of smooth tip two pass channels. Investigations were carried out at different Reynolds numbers ranging from 200000 to 450000. It was found that if pins are provided at the corners the local heating of the tip at corners is avoided. A heat transfer augmentation of about 1.3 times was observed as compared to a smooth surface with pressure drop of less than $6 \%$. Hence the proper arrangement and number of pin fins is recommended for augmentation of heat transfer over the turbine blade tip.
\end{abstract}

Keywords - Turbine Tip Cooling, Turbulence, numerical simulation, hotspots. $* * *$

\section{INTRODUCTION}

Modern gas turbines operate at very high temperatures for increasing the efficiency and performance of the turbines. But these high temperatures may exceed the material melting temperature of the turbine blades. Hence proper cooling system must be employed for the cooling of the turbine blades for their long life. The leading edge of the turbine blade airfoil is cooled by using impingement cooling with film cooling, the middle portion is cooled by using rib turbulated cooling and the trailing edge is cooled by using pin fin cooling with ejection. The cooling of the turbine blades must include all the regions exposed to hot gases. One of such regions of a blade in case of high pressure turbines is the tip of the blade. For the mechanical and thermal expansion of the blades a clearance gap is provided between the turbine blade tip and the shroud/ fixed casing of the turbine. But due to this clearance gap, leakage of hot gases occurs mainly due to the difference between the pressure side and suction side of the blade. And this gap cannot be completely eliminated since it will cause rubbing of the blades to the casing thereby causing damage to the turbine. Hence the cooling of the turbine blade tip must be given a special attention for safe and efficient working of the turbines. One very common method of cooling is by providing serpentine passages in the middle portion of the turbine blade. Fig 2 shows the typical serpentine passages that are commonly used for the internal cooling of turbine blades.

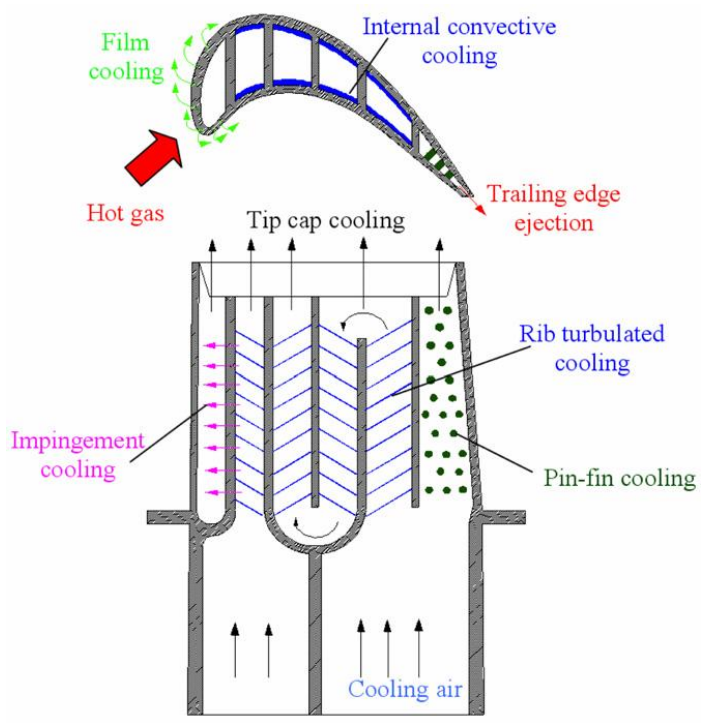

Fig 1 Typical cooling techniques of turbine blade 
There are several publications available discussing the effects of providing ribs/vanes/pin fins inside these serpentine passages which improve the heat transfer by considerable amount. A slight modification in the method of tip cooling involves direct geometrical modifications to the internal tip of the turbine blades. Ron S. Bunker [1] experimentally investigated the effect of providing pin arrays to the internal tip cap of turbine blades. Five different configurations were used to compare the heat transfer coefficients. A smooth surface, two different heights of aluminium pin arrays, one more closely spaced array and one pin array made of insulating material were experimentally tested. As compared to smooth tip it was found that the provision of pin arrays showed heat transfer coefficient improved by a factor of 2.1. Also this method resulted in negligible pressure drop as compared to that of a smooth surface of the turbine internal tip. Gongnan Xie and Bengt Sunden [2] simulated the same geometry as given by Bunker. Only here the difference was provision of hemispherical dimples/concave dimples on the internal tip cap instead of arrays in case of Bunker's experiment. Here the flow was numerically simulated and studied by using two different heights of dimples were used. It was found that the heat transfer was doubled compared to smooth tip by provision of dimples on the surface of internal tip cap of the turbine blades. In yet another analysis Gongnan Xie [3] carried out numerical simulations for six different arrangements of the guide rib/vanes in a two pass serpentine passage.

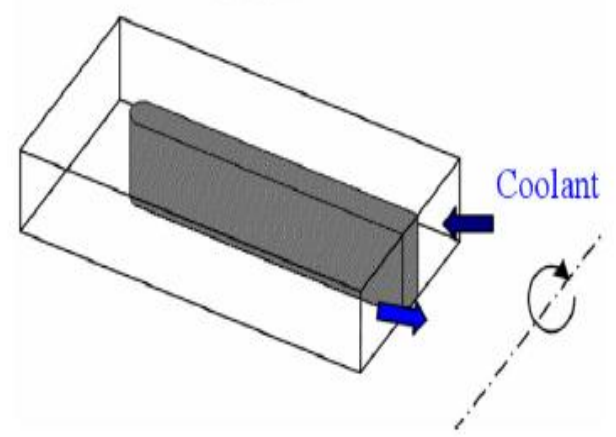

Fig 2 A typical two pass serpentine passages inside a turbine blade [2]

The guide ribs/vanes were placed at different locations inside the passage and their effect on the heat transfer coefficient was examined numerically using computational fluid dynamics technique. It was concluded that the tip heat transfer coefficients of channels with guide ribs/vanes are upto $65 \%$ higher than those of a channel without the provision of guide ribs/vanes. Another conclusion made was that there would be improved heat transfer if the guide ribs/vanes are properly placed inside the channel. But this method was found o be less effective as compared to the direct geometrical modifications as proposed by Bunker. Another option of tip cooling was proposed by Gongnan Xie and Bengt Sunden [4] which stated the use of pin fins for the cooling of tip of the turbine blades. Also noteworthy was the point that the heat transfer enhancement for the pin fins is higher than that for the pin arrays once these pin fins are properly placed on the tip of the blade. A very limited data is available and few researches have been conducted on the cooling of turbine blades by direct geometrical modifications to the internal tip cap. All the publications explaining this method have considered smooth channels without ribs i.e. assuming that the channels have constant heat transfer surfaces. Hence the heat transfer enhancement for turbine tip has been studied by considering smooth channels instead of ribbed ones.

\section{GEOMETRY OF PHYSICAL MODEL}

The physical model considered for this study is as shown in the Fig 3. It consists of a two pass rectangular channel with inlet and outlet sections having a cross sectional area of 6.99 $\mathrm{x} 13.97$ sq.cm. The hydraulic diameter from the geometry is calculated as $9.32 \mathrm{~cm}$. A gap of $8.89 \mathrm{~cm}$ is assumed from the tip surface to the turn surface i.e. between the divider and the tip wall. The thickness of the internal separation tip is $2.54 \mathrm{~cm}$. the height of the two pass channel is $13.97 \mathrm{~cm}$. Rest of the features of the geometry are similar to those of Bunker [1] for a smooth tip two pass channel. But the geometry varies at the tip surface when the case of pins is considered

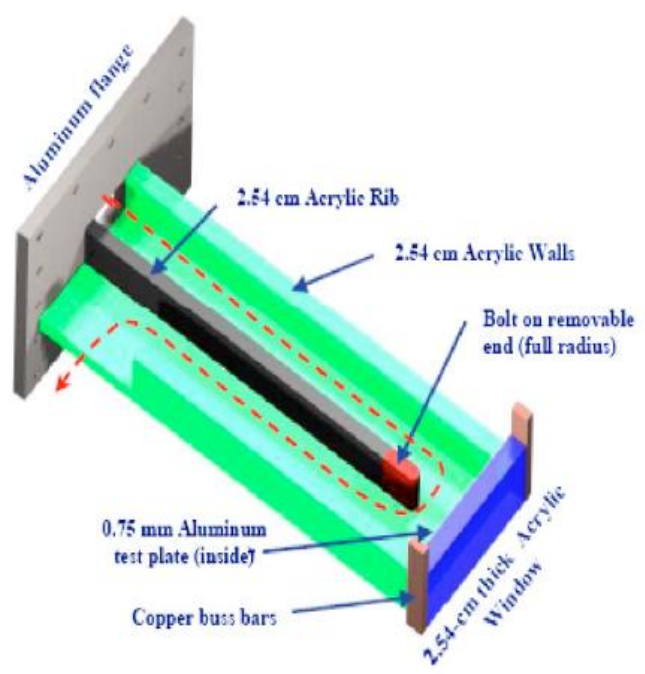

Fig 3 Experimental model [1]

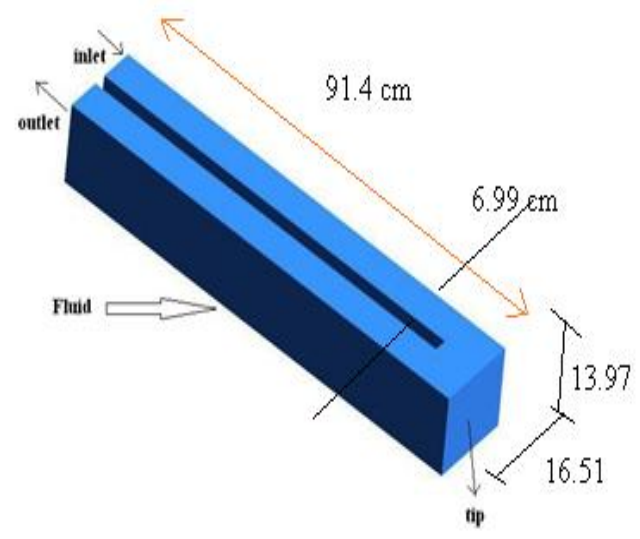

Fig 4 Simulated model 


\section{DESCRIPTION OF COMPUTATIONAL} MODEL

\subsection{Summary of Model}

The numerical model considered in this study is a two pass serpentine channel with sharp $180^{\circ}$ turn. A schematic diagram of the geometrical models used in this study is shown in Fig. 4. The two-pass channels have rectangular cross-section with an aspect ratio of 1:2 (the flow spanwise width in the y-direction, is the half of the channel height in the $\mathrm{z}$-direction), where the shorter walls are the turbine pressure side and suction side. Each channel is 139.7 and $69.9 \mathrm{~mm}$ with a hydraulic diameter of $93.13 \mathrm{~mm}$. The lengths of the inlet channel (first-pass) and the outlet channel (second-pass) are about ten hydraulic diameters, and both the inlet and outlet channels are smooth without any turbulators. The internal separation rib (divider) is assumed to be $25.4 \mathrm{~mm}$ thick so that the full tip-wall cap section is 139.7 by $165.1 \mathrm{~mm}$. A distance of $88.9 \mathrm{~mm}$ is used for the flow gap between the divider and the tip-wall. The smoothtip two-pass channel is used as a baseline for performance comparison with the protruded-tip two-pass channels. Other numerical details are similar to those of Bunker's geometrical model. The surfaces studied for the internal tip are also similar to those studied by Bunker [1].

\subsection{Computational Details}

To investigate the temperature distributions and the heat transfer augmentation in the three dimensional flow field, a $\mathrm{k}-\varepsilon$ turbulence modeling was selected. The pressure and velocity were linked by Semi Implicit Method for Pressure Linked Equation (SIMPLE) scheme. The finite modeling was conducted in Ansys Fluent 14.0. The Fluent code uses finite volume method to solve the governing equations of the flow. Mesh generation was done in Ansys Mesh Modeler. This study examined turbulent flow and the heat transfer characteristics for a smooth tipped surface and the protruded surface were also checked for enhancement in heat transfer

\subsection{Selection of Turbulence Model}

A realizable k- $\varepsilon$ turbulence model was selected based on the previous studies. The realizable $\mathrm{k}-\varepsilon$ model is very effective in case of flows which involve sudden turns involving sharp streamline curvatures. As the flow involves a $180^{\circ}$ sharp turn it is recommended to use this turbulence model for the current simulation. The flow features like separation, recirculation and impingement are quite accurately resolved by this turbulence model.

\subsection{Governing Equations}

The governing equations for the flow are as expressed below

Continuity equation [2]

$$
\frac{D \rho}{D t}+\rho \nabla \cdot V=0
$$

Momentum equation

$\mathrm{X}$-momentum

$$
\rho \frac{D u}{D t}=-\frac{\partial p}{\partial x}+\frac{\partial \tau_{x x}}{\partial x}+\frac{\partial \tau_{y x}}{\partial y}+\frac{\partial \tau_{z x}}{\partial z}+\rho f_{x}
$$

Y-momentum

$$
\rho \frac{D v}{D t}=-\frac{\partial p}{\partial y}+\frac{\partial \tau_{x y}}{\partial x}+\frac{\partial \tau_{y y}}{\partial y}+\frac{\partial \tau_{z y}}{\partial z}+\rho f_{y}
$$

Z-momentum

$$
\rho \frac{D w}{D t}=-\frac{\partial p}{\partial y}+\frac{\partial \tau_{x z}}{\partial x}+\frac{\partial \tau_{y z}}{\partial y}+\frac{\partial \tau_{z z}}{\partial z}+\rho f_{z}
$$

Energy Equation for fluid [2]

$$
\frac{\partial u_{i} T}{\partial x_{i}}=\frac{\partial}{\partial x_{i}}\left(\left(\frac{\mu}{\operatorname{Pr}}+\frac{\mu_{t}}{\operatorname{Pr}}\right) \frac{\partial T}{\partial x_{i}}\right)
$$

\subsection{Boundary Conditions}

Although the heat transfer on the leading and trailing walls are important for gas turbine blade design, the heat transfer enhancement of a protruded tip-wall over that of a smooth tip-wall is the major concern of this paper. Therefore, except for the external smooth tip-wall, the remaining walls are assumed to be adiabatic. A constant heat flux is prescribed on the bottom wall. No-slip velocity conditions are applied at all walls. A uniform velocity (different for different Re) and temperature are set at the inlet and an outflow condition is chosen at the outlet. A turbulence intensity level of $10 \%$ and the hydraulic diameter are used to compute the turbulence quantities at the inlet. Due to the conjugation of fluid and solid heat transfer, the boundary conditions for the interfaces between the dimple surfaces and the internal dimpled tip-cap surface are automatically coupled. The fluid is assumed to be incompressible with constant thermal physical properties and the flow is assumed to be three dimensional, turbulent, steady and non-rotating. The working fluid is dry air. In this study, because of high Reynolds numbers and the complicated computational model, the standard wall functions of the k- $\varepsilon$ model 2 equation models are applied on the walls for the near wall treatment. The convergence criterion for continuity, momentum, $\mathrm{k}$ and e equations is $10^{\wedge} 4 \mathrm{but} 10^{\wedge} 7$ for the energy equation.

\subsection{Grid Dependence Study}

A grid dependence test is carried out in order to select the appropriate mesh before simulating the flow. The details of the mesh independence will be included in a separate study paper. For the grid independence test four different grid were chosen- 18410 cells, 54321 cells, 91152 cells and 115842 cells studied. Various parameters like temperature, 
pressure and eddy viscosity were evaluated over these grids. It was found that the grids with 91152 cells and 115842 cells showed the closest results amongst the four. Hence in order to avoid the computational time and also to reduce computational resources the grid with 91152 cells was selected for further simulations.

\section{RESULTS AND DISCUSSIONS}

\subsection{Definition of Parameters}

Before explaining the results the following parameters are defined

$$
f=\frac{(\Delta p)}{\left(2 \rho u_{i} 2\right)} \cdot \frac{D_{h}}{L}
$$

The local Nusselts number is given by

$$
N u(i)=\frac{\left(q_{w}\right)}{\left(T(i)-T_{f}\right)} \cdot \frac{D_{h}}{\lambda}
$$

The overall Nusselts number is given by

$$
N u=\frac{h D_{h}}{k}
$$

\subsection{Validation of Model}

Before finalizing the simulation and processing further calculations we need to validate the results

It is seen from Fig 5 and Fig 6 that the values of the numerical results are in accordance with the experimental results of Bunker [1] with a maximum deviation less than 15 $\%$. The results have been simulated using the realizable $\mathrm{k}-\varepsilon$ turbulence model with a standard wall function. A good agreement between the experimental results and the current computational model has been achieved. This validates our numerical simulations.

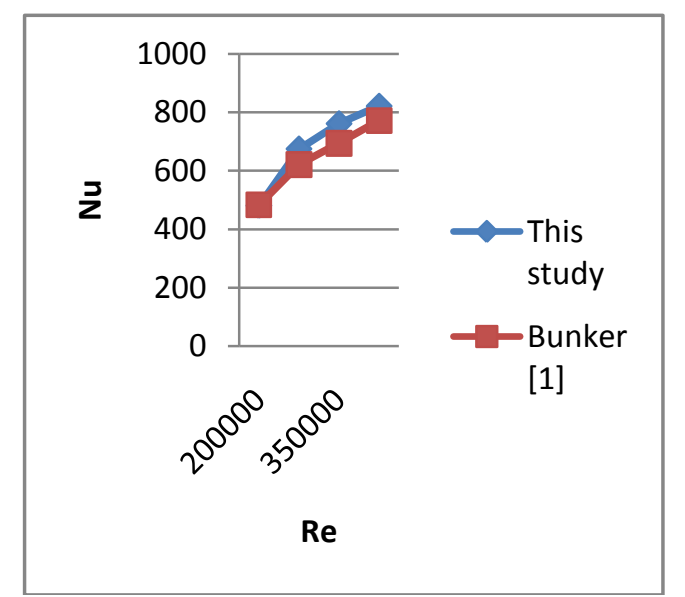

Fig. 5 Nusselts number for current study and Bunker's [1] experimental results for a smooth tip two pass channel

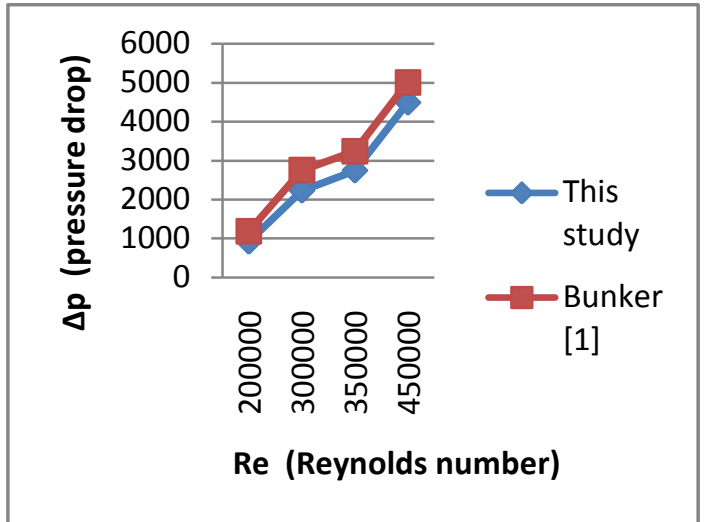

Fig. 6 Pressure drop for current study and Bunker's [1] experimental results for a smooth tip two pass channel

After the model validation the results have been computed for different configurations of the tip i.e. by modifying the surface of the tip with arrangement of pins at different locations and with different dimensions as explained further. Also the mass flow rates from numerical and calculated results have been compared. Both the results give almost the same values indicating the simulated model is valid. The values are a listed in the Table 1 .

Table 1

\begin{tabular}{|l|l|l|l|l|l|}
\hline $\begin{array}{l}\text { Param } \\
\text { eter }\end{array}$ & Study & $\begin{array}{l}\mathrm{Re}=20 \\
0000\end{array}$ & $\begin{array}{l}\mathrm{Re}=30 \\
0000\end{array}$ & $\begin{array}{l}\mathrm{Re}=35 \\
0000\end{array}$ & $\begin{array}{l}\mathrm{Re}=45 \\
0000\end{array}$ \\
\hline & $\begin{array}{l}\text { Nume } \\
\text { rical }\end{array}$ & 0.3601 & 0.5624 & 0.6302 & 0.8102 \\
\cline { 2 - 6 } & $\begin{array}{l}\text { Calcul } \\
\text { ated }\end{array}$ & 0.3748 & 0.5624 & 0.6562 & 0.8434 \\
$\begin{array}{l}\text { Flow } \\
\text { Rate( } \\
\mathrm{kg} / \mathrm{s})\end{array}$ & $\begin{array}{l}\text { \% } \\
\text { deviat } \\
\text { ion }\end{array}$ & 3.99 & nil & 3.99 & 3.99 \\
\hline
\end{tabular}

In order to understand the flow patterns and the temperature regions the temperature contours over the tip surface have been plotted. Fig 7 shows the temperature contours for a smooth surface at a Reynolds number $\mathrm{Re}=200000$. From the temperature contours it is seen that the corners of the tip are the portions which are more vulnerable to high temperatures.

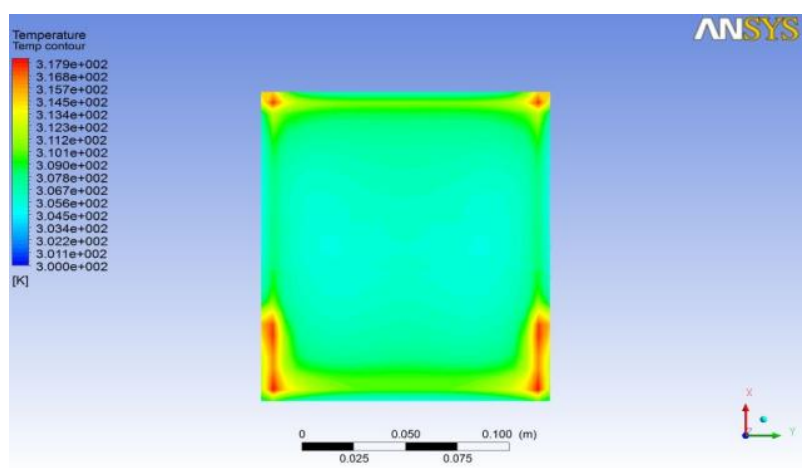

Fig. 7 Temperature contour for smooth channel at $\mathrm{Re}=200000$ 


\section{OVERALL COMPARISONS}

Two types of surfaces were compared. The configuration of the two surfaces were same only the heights of the pins used at the corners were different, more height in the latter case. The configuration is as shown in the fig. 8 .

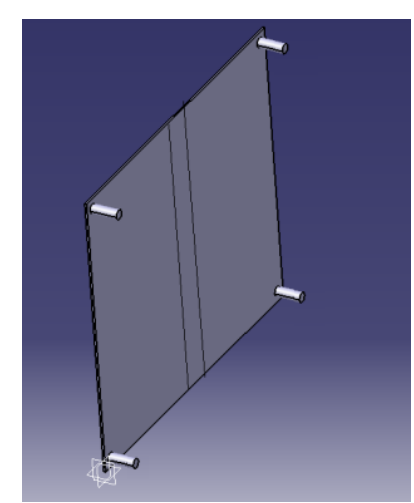

(a)

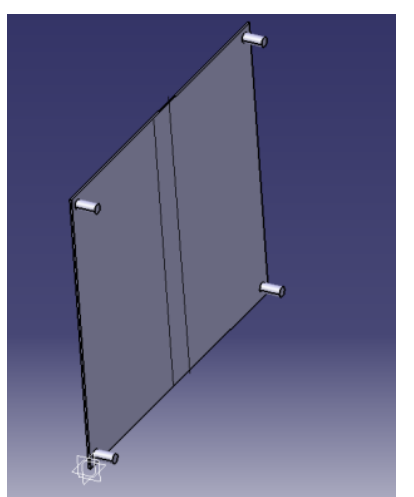

(b)
Fig. 8 a) Case $I-D=0.5 \mathrm{~cm}, H=1 \mathrm{~cm}(H / D=1: 2)$ b) Case II $\mathrm{D}=0.4 \mathrm{~cm}, \mathrm{H}=0.8 \mathrm{~cm}(\mathrm{H} / \mathrm{D}=1: 2)$

Case I: - Pin fins of diameter $5 \mathrm{~mm}$ with a height of $10 \mathrm{~mm}$. The area added by the fins accounts to 1.766 sq.cm by each pin fin. Therefore the total area added by 4 pins for Case I is 7.065 sq.cm

Case II: - Pin fins of diameter $4 \mathrm{~mm}$ with a height of $8 \mathrm{~mm}$. The area added by the fins accounts to 1.1304 sq.cm by each pin fin. Therefore the total area added by 4 pins for Case I is 4.5216 sq.cm

\subsection{Streamlines of Case I \& Case II as Compared to}

\section{Smooth Surface}

From fig 7.16 it is seen that the flow does not produce any type of whirls while taking the turn. It is also evident that the flow interacts with the pin fins at the corners thus enhancing the heat transfer of the tip at the corners as well as over the other surface.

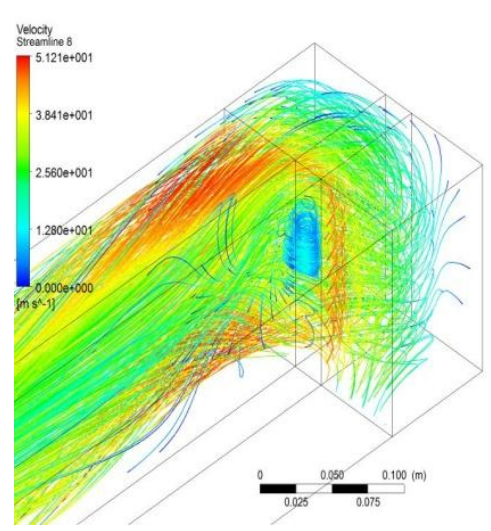

(a)

ansis

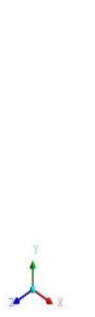

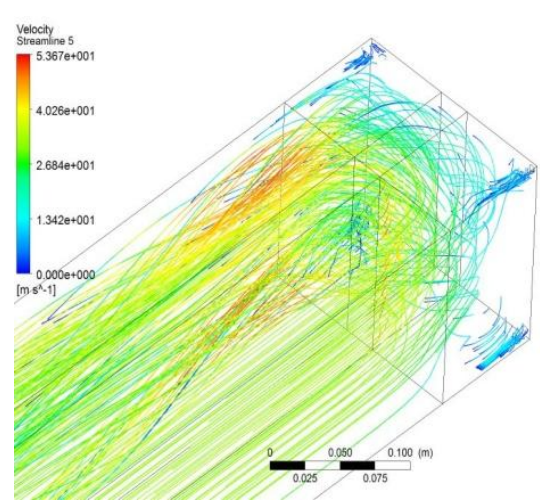

aNsYS

(b)

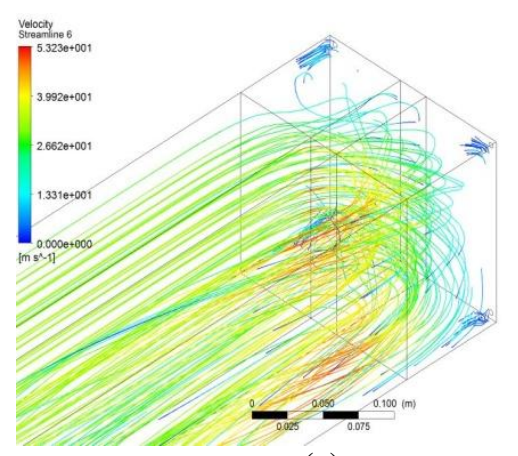

aNSYS

(c)

Fig 9 a) Streamlines of smooth surface at $R e=200000$ b) Streamlines of pin finned surface Case I at $\mathrm{Re}=200000 \mathrm{c}$ ) Streamlines of pin finned surface Case II at $\mathrm{Re}=200000$

\subsection{Velocity Vectors of the Three Surfaces}
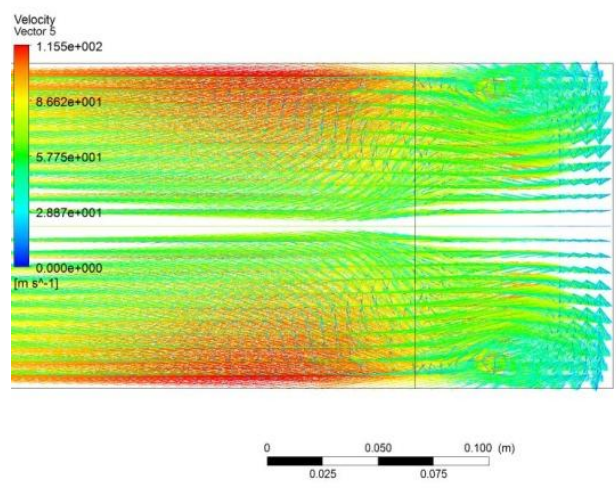

(a)
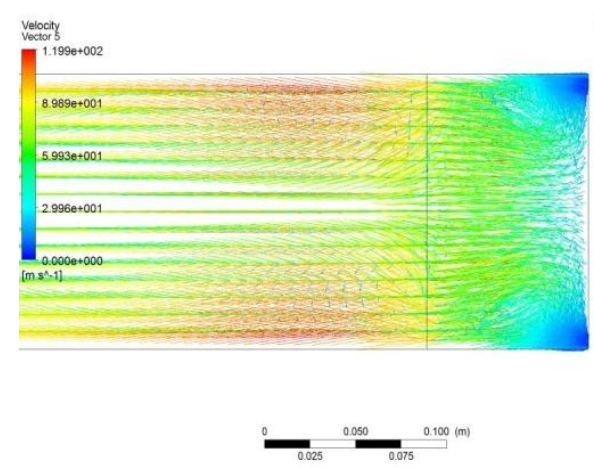

$\because$

(b) 

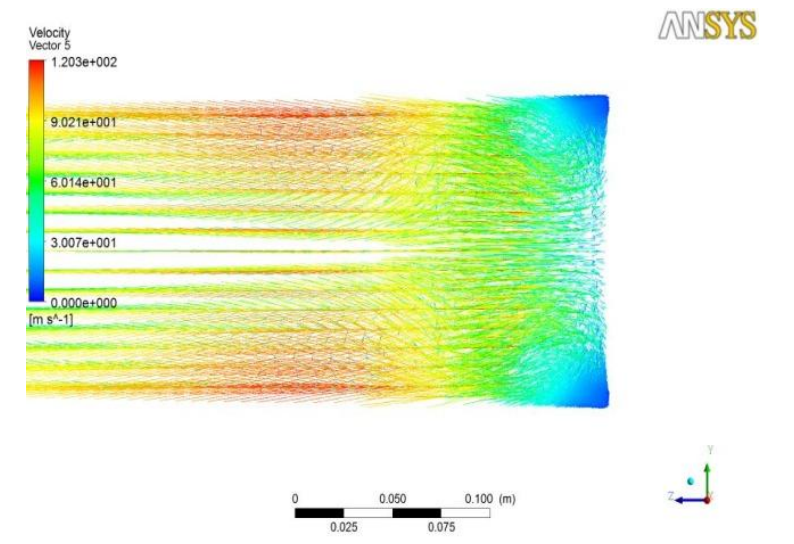

(c)

Fig 10 Velocity Vectors of three surface at $\mathrm{Re}=450000$

Fig 10 shows the velocity vectors of smooth tip two pass channel and pin finned tip two pass channel. It can be clearly seen that due to the pin fins turbulence is created at the corners of the tip region. The flow interacts with surface of the tip due to the pins and also remains near the pins for a considerable amount of time. After heating there is time for the flow to mix with the incoming cooling fluid, thereby improving cooling at the tip section.

\subsection{Comparisons of the Three Surfaces}

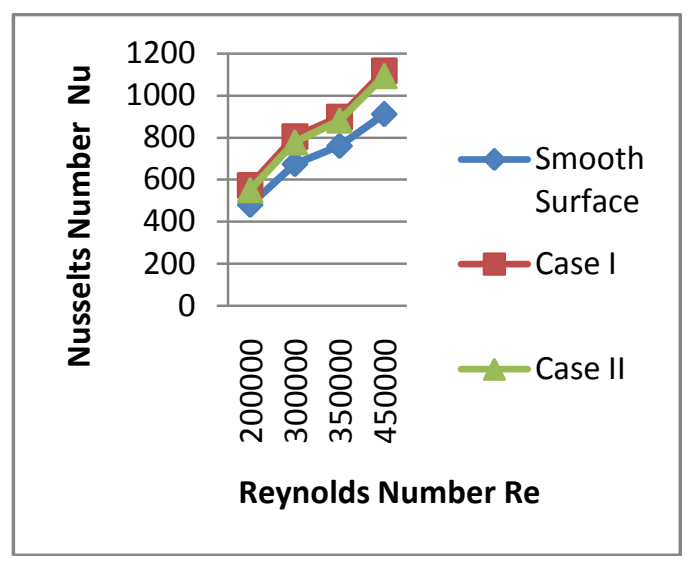

(a)

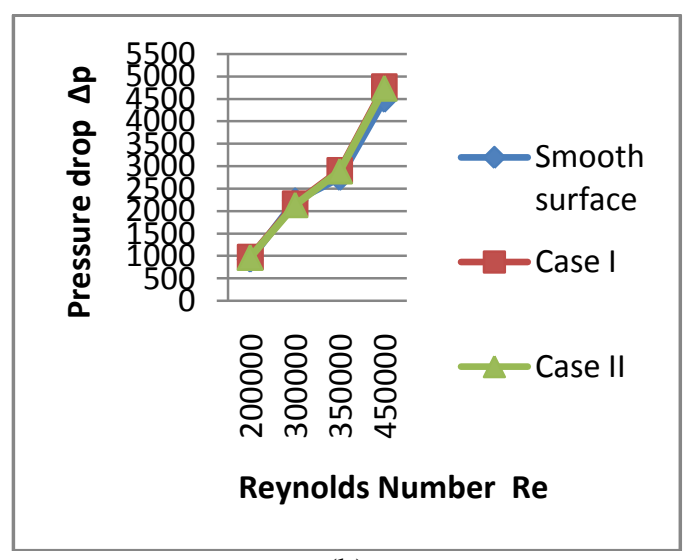

(b)

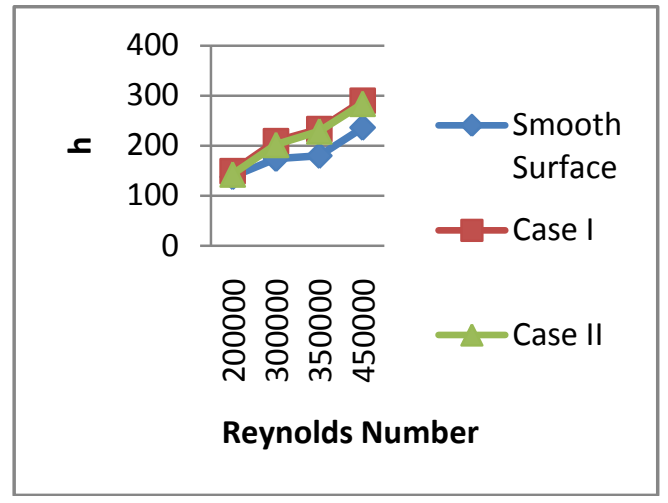

(c)

Fig 11.a) Nusselts number comparison of three surfaces b) Pressure drop comparison of three surfaces c) Heat transfer coefficient comparison of three surfaces

From fig 11 it can be seen that the values of Nusselts number and surface heat transfer coefficient are greater for the pin finned surfaces as compared to the smooth surface. The pressure drop values are alost same for all the three surfaces.

\section{CONCLUSIONS}

From the above studies the following conclusions can be made

- Pin fins can prove to be a great heat transfer enhancement tool if configured in proper numbers and arrangement.

- Compared to the smooth surface the pin finned surfaces provided an additional area for heat transfer.

- The pin fins provided at the corners and at the periphery of the tip force the vortices generated towards the tip wall thereby improving the turbulent mixing of the heated fluid with the incoming cold fluid.

- The pin fins provided also helped in uniform distribution of heat over the tip.

- The heat transfer enhancement of the pin finned surfaces is about 1.5 times higher than that of the smooth surface.

- All the augmentation has been obtained at a pressure drop of less than $10 \%$.

\section{REFERENCES}

[1] Ronald S. Bunker," The Augmentation of Internal Blade Tip-Cap Cooling by Arrays of Shaped Pins," Journal of Turbomachinery, OCTOBER 2008, Vol. 130 / 041007-1

[2] Gongnan Xie, Bengt Sundén.” Numerical predictions of augmented heat transfer of an internal blade tip-wall by hemispherical dimples," International Journal of Heat and Mass Transfer 53 (2010) 5639-5650.

[3] Gongnan Xie, Bengt Sundén, "Computational Analysis of Pin-Fin Arrays Effects on Internal Heat 
Transfer Enhancement of a Blade Tip Wall," Journal of Heat Transfer, MARCH 2010, Vol. 132 / 031901 1

[4] Gongnan Xie, Bengt Sundén,Weihing Zhang,"Comparisons of Pins/Dimples,Protrusions cooling concepts for a turbine blade tip wall at high Reynolds numbers," Journal of Heat Transfer, June 2011,Vol.133/061902-1

[5] Robert KIML, Sadanari MOCHIZUKI, Akira MURATA and Matej SULITKA, "Rib-Induced Secondary Flow Structures inside a High Aspect Ratio Trapezoidal Channel," Proceedings of the International Gas Turbine Congress 2003 Tokyo November 2-7, 2003.

[6] Je-Chin Han, "Recent Studies in Turbine Blade Cooling," International Journal of Rotating Machinery, 10(6): 443-457, 2004.

[7] Ravi Teja, S. Krishna Chaitanya, "Case study on Turbine Blade Internal Cooling," International Journal of Engineering Research \& Technology ISSN: 2278-0181, (IJERT) Vol. 2 Issue 3, March 2013 ISSN: 2278-0181.

[8] Ana Paula P. dos Santos, Claudia R. Andrade and Edson L. Zaparoli, "Comparison of Different Gas Turbine Inlet Air Cooling Methods," World Academy of Science, Engineering and Technology 612012.

[9] S. Gupta, A. Chaube, Verma, "Review on Heat Transfer Augmentation Techniques: Application in Gas Turbine Blade Internal Cooling," Journal of Engineering Science and Technology Review 5 (1) (2012) 57-62. 